\title{
Urinary Kidney Injury Molecule 1 (U-KIM-1) as a Predictor of Lupus Nephritis
}

\author{
SALWA S. EL-GENDI, M.D.*; SAMIR K. ABDUL-HAMID, M.D.*; \\ ASMAA O. AHMED, M.D.** and SALMA M. MOHAMMED, M.Sc.* \\ The Departments of Internal Medicine* and Clinical Pathology**, Faculty of Medicine, Assiut University, Assiut, Egypt
}

\begin{abstract}
Background: Early detection of kidney affection in systemic lupus erythrematosus patients and proper monitoring of lupus nephritis activity is very important step in improving lupus nephritis outcome. Urinary kidney injury molecule-1 is considered as a promising biomarker of kidney injury.
\end{abstract}

Aim of Study: Use of urinary kidney molecule-1 as an early biomarker of lupus nephritis in systemic lupus erythrematosus patients and detection of correlation between $\mathrm{U}_{-}$ KIM-1 and disease activity lupus nephritis.

Methods: Our study included 45 systemic lupus patients and 15 controls. Patients divided into 3 groups; group A (SLE without lupus nephritis), group B (SLE with inactive lupus nephritis) \& group C (SLE with active lupus nephritis). All patients included in this study are subjected to the following investigations: Urinary Kim-1, complete blood picture, serum urea \&creatinine, urine analysis, 24 hour urinary proteins, estimated GFR by CKD-EPI Creatinine Equation, complement $3 \& 4$, serum albumin, Anti-dsDNA antibody \& ESR.

Results: Generally U-KIM-1 was significantly higher in our patients with SLE compared with the healthy control group. Also, patients with nephritis had significantly higher level in comparison to those without nephritis. Our study also showed that patients with active nephritis had significantly higher level of U-KIM-1 in comparison to those patients with inactive nephritis. U-KIM-1 had negative moderate significant correlation with eGFR $[-0.62(0.001)]$, and Complement C3 $[-0.51(0.001)]$ and had positive moderate significant correlation with serum creatinine [0.44 (0.001)], and renal SLEDAI $[0.62(0.001)]$. There was also a strong positive significant correlation between U-Kim-1 and 24h-urinary proteins collection $[0.71(0.001)]$. Although there was negative weak correlation between U-Kim-1.

Conclusion: Urinary kidney injury molecule -1 (KIM-1) is considered a promising biomarker that can be used in early detection and initial diagnosis of renal affection in systemic

Correspondence to: Dr. Salwa S. El-Gendi, The Department of Internal Medicine, Faculty of Medicine, Assiut University, Assiut, Egypt lupus erythrematosis, monitoring of activity of lupus nephritis. And hence, can also be used in monitoring response to treatment.

Recommendation: Wider studies are recommended to detect cut off points of U-Kim-1 in lupus nephritis \& active lupus nephritis.

Key Words: SLE - U Kim-1 - Lupus nephritis.

\section{Introduction}

SYSTEMIC lupus erythrematosus (SLE) is a chronic inflammatory disease that has variable manifestations and follows a relapsing and a remitting course. More than $90 \%$ of SLE occur in women, frequently starting at child bearing age. It is characterized by an autoantibody response to nuclear and cytoplasmic antigens. It can affect any organ system, but it mainly involves the skin, joints, kidneys, blood cells, and nervous system [1].

Lupus nephritis, one of the most serious manifestations of systemic lupus erythematosus, usually arises within 5 years of diagnosis. Renal involvement or lupus nephritis (LN) still occurs in up to $50 \%$ of SLE patients [2]

Severe LN has been reported to result in endstage kidney disease at a rate of 10\%-26\% [1] which may be a result of the difficulty in recognizing a flare early enough to affect the course of the disease; since, prompt diagnosis and earlier treatment lead to better outcomes [3].

LN frequently coexists with acute and chronic pathological renal change, and it is important when determining the renal prognosis of patients to understand the degree of renal damage without performing invasive tests [4]. Thus, defining an 
early and reliable biomarker of kidney involvement in SLE is highly desirable [5] .

Kidney injury molecule-1 (KIM-1) is a transmembrane protein with Ig-like and mucin domains in its ectodomain. It is believed to play a role in tubulo-interstitial damage [6]

Urinary KIM-1 levels are strongly related to tubular KIM-1 expression in experimental and in human renal disease [7]. Studies in human also indicated that urinary KIM-1 was sensitive and specific marker ofkidney injury as well as predictors of outcome [8]

\section{Patients and Methods}

That study is case control study. It includes 45 patients who admitted in Rheumatology and Nephrology Units or coming follow-up out patient Clinics at Assiut University Hospital from April 2016 - Feb. 2017 and 15 healthy (control). Patients who are divided into 3 groups:

Group A: Include (15) SLE patients without lupus nephritis.

Group B: Include (15) SLE patients with inactive lupus nephritis.

Group C: Include (15) SLE patients with active lupus nephritis.

All of the patients are diagnosed according to the American College of Rheumatology(ACR) diagnostic criteria $[9,10]$. The disease activity is assessed by the SLEDAI. A SLEDAI score $\geq 4$ was taken as an indicator of high levels of disease activity [11]. For renal involvement, renal SLEDAI (rSLEDAI) was used to assess kidney disease activity. The score consists of the four kidneyrelated parameters: Hematuria, pyuria, proteinuria, and urinary casts. Scores for the rSLEDAI can range from 0 (inactive renal disease) to a maximum of 16. A rSLEDAI score $\geq 4$ was taken as an indicator of active $\mathrm{LN}$ [12]. Inactive $\mathrm{LN}$ was also defined as an rSLEDAI score of $<4$ [13]. Systemic lupus patients who are diabetic, hypertensive or pyelonephritic or End Stage Renal Disease were excluded from Study. All patients included in this st udy are subjected to the following investigations:

1- Urinary Kim-1.

2- Complete blood picture.

3- Serum urea \& creatinine.

4- Urine analysis.

5- 24 hour urinary protiens.

6- Estimated GFR by CKD-EPI Creatinine Equation.
7- Complement $3 \& 4$.

8- Serum albumin.

9- Anti-dsDNA antibody.

10- Erythrocyte sedimentation rate (ESR).

\section{Statistical analysis:}

Data was collected and analyzed using SPSS, version 20. Continuous data was expressed in form of mean \pm SD while nominal data was expressed in form of frequency (percentage). Chi ${ }^{2}$ test was used to compare nominal data in different groups. ANOVA test was used to compare means of different variables in more than two groups followed by Post-Hoc test to compare between each group and others. Pearson correlation was used to test correlation between UKim-I and serum creatinine, C3, C4, 24h-urinary proteins and renal SLEDAI. $p$ value was significant if $<0.05$.

\section{Results}

Table (1) showed the demographic data of the studied subjects. It showed that there was female predominance- $43(72 \%)$ - and yet sex distribution of the different groups had no statistical difference between the groups with $p$-value was 0.87 .

Mean ( \pm SD) age of all studied subjects was $29.11 \pm 6.07$ years. It was noticed that there was no statistical difference between the groups regarding age with $p$-value was 0.64 .

Clinical data of the studied patients were also shown in Table (1) Positive Anti-ds DNA was the most frequent criterion that presented in 36 (80\%) patients; 15,9 and 12 patients were with active nephritis, inactive nephritis and without nephritis respectively. Discoid rash was the least frequent criterion where only three $(6 \%)$ patients had discoid rash; two of them were without nephritis while the other patient was with active nephritis. Cutaneous manifestations including (malar rash, photosensitivity and discoid rash) were found in $17(38 \%)$ patients.

It was noticed that positive Anti-ds DNA and ANA were the most frequent criteria in patients without nephritis where each of them occurred in $12(80 \%)$ patients.

The most frequent criteria in patients with inactive nephritis were hematological affection and positive ANA presented in $11(73.3 \%)$ and 11 $(73.3 \%)$ patients respectively.

All patients with active nephritis in the study had positive Anti-ds DNA, while $12(80 \%)$ patients of them had hematological affection. 
Table (1): Demographic characteristics of studied subjects.

\begin{tabular}{|c|c|c|c|c|c|}
\hline Variables & $\begin{array}{l}\text { Patients } \\
\text { without nephritis } \\
(\mathrm{n}=15)\end{array}$ & $\begin{array}{l}\text { Patients with } \\
\text { inactive nephritis } \\
(\mathrm{n}=15)\end{array}$ & $\begin{array}{l}\text { Patients with } \\
\text { active nephritis } \\
\quad(n=15)\end{array}$ & $\begin{array}{l}\text { Control group } \\
\qquad(\mathrm{n}=15)\end{array}$ & $p$-value \\
\hline Age (years) & $37.89 \pm 11.09$ & $29.73 \pm 8.64$ & $26.98 \pm 6.04$ & $30.02 \pm 7.94$ & 0.64 \\
\hline $\begin{array}{l}\text { Sex: } \\
\quad \text { Male n (\%) } \\
\text { Female n }(\%)\end{array}$ & $\begin{array}{l}2(13.3) \\
13(86.7)\end{array}$ & $\begin{array}{l}3(20) \\
12(80)\end{array}$ & $\begin{array}{l}3(20) \\
12(80)\end{array}$ & $\begin{array}{l}6(40) \\
9(60)\end{array}$ & 0.87 \\
\hline $\begin{array}{l}\text { Malar rash, n (\%) } \\
\text { Discoid rash, n (\%) } \\
\text { Photosensitivity, n (\%) } \\
\text { Oral ulcer, n (\%) } \\
\text { Arthritis, n (\%) } \\
\text { Serositis, n (\%) } \\
\text { Renal affection, n (\%) } \\
\text { Neurological affection, n (\%) } \\
\text { Hematology affection, n (\%) } \\
\text { Anti-ds DNA, n (\%) } \\
\text { Anti-nuclear antibody, n (\%) }\end{array}$ & $\begin{array}{l}3(20) \\
2(13.3) \\
3(20) \\
4(26.7) \\
11(73.3) \\
5(33.3) \\
0 \\
2(13.3) \\
10(66.7) \\
12(80) \\
12(80)\end{array}$ & $\begin{array}{l}2(13.3) \\
0 \\
2(13.3) \\
3(20) \\
9(60) \\
5(33.3) \\
15(100) \\
0 \\
11(73.3) \\
9(60) \\
11(73.3)\end{array}$ & $\begin{array}{l}3(20) \\
1(6.7) \\
4(26.7) \\
3(20) \\
9(60) \\
4(26.7) \\
15(100) \\
2(13.3) \\
12(80) \\
15(100) \\
7(46.7)\end{array}$ & & \\
\hline
\end{tabular}

- Continuous data was expressed in form mean SD while nominal data in form of frequency (percentage). $p$-value was significant if $<0.05$. N: Number

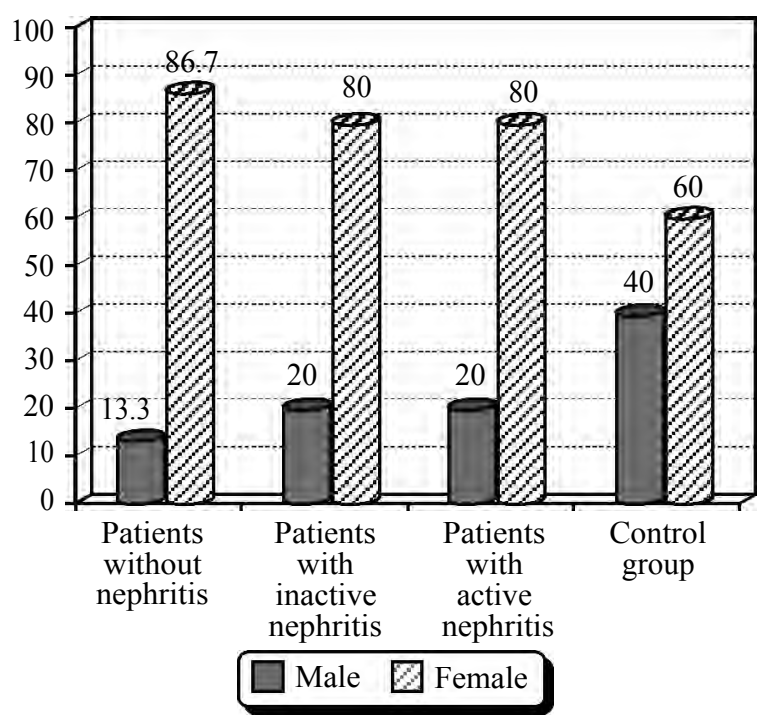

Fig. (1): Sex distribution in the study.

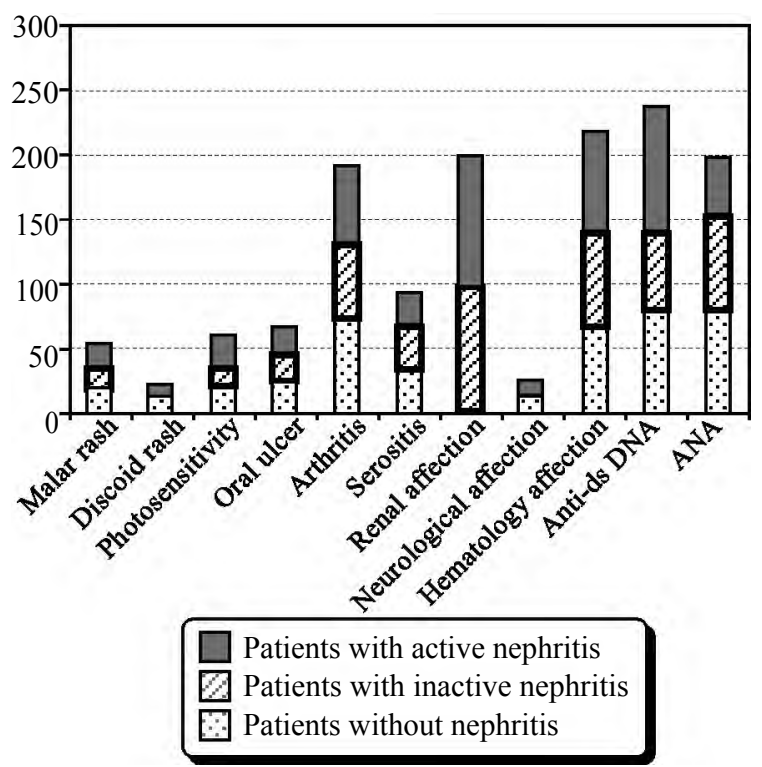

Fig. (2): Clinical Data of the studied patients

\section{Laboratory data of studied groups:}

- Complete blood picture:

Regarding hemoglobin, $\mathrm{MCV}, \mathrm{MCH}, \mathrm{WBCs}$ and platelets; it was noticed that WBCs, MCV and $\mathrm{MCH}$ had no significant different between different groups with $p$-value $0.94,0.19$ and 0.12 respectively.

It was found that control group had significantly higher platelets count and hemoglobin $(p=0.001)$ level while the three groups of patients had no statistical differences between each other regarding $\mathrm{Hb}$ and platelets count.

\section{- Serum albumin:}

There was significant differences between the different groups of patients regarding serum albumin level $(p=0.04)$. Control group and patients without nephritis had significantly higher $(p<0.05)$ level in comparison to those with inactive nephritis and those with active nephritis where serum albu$\min$ was $38.13 \pm 2.73 \mathrm{~g} / \mathrm{L}, 35.23 \pm 4.04,29.93 \pm 5.56$ and $28.06 \pm 4.35$ and respectively.

It was noticed that serum albumin had no significant differences between those with active nephritis and those with inactive nephritis; 28.06 \pm 4.35 vs. $29.93 \pm 5.56$ with $p=0.33$.

\section{- Kidney function tests:}

\section{1- Serum creatinine and serum urea:}

Patient with nephritis whether active or inactive had significant raised serum creatinine and blood urea nitrogen in comparison to those patients without nephritis and the control group $(p<0.05)$.

It was noticed that there was no significant difference regarding blood urea nitrogen and serum 
creatinine between patients with active nephritis and those with inactive nephritis and between those without nephritis and the control group $(p>0.05)$

\section{2- 24h-urinary protein:}

Patients with active nephritis had significantly higher 24-h urinary protein $(1412.89 \pm 234.78 \mathrm{mg}$ / $24 \mathrm{~h})$ in comparison to other groups; $1117.98 \pm$ $201.34 \mathrm{mg} / 24 \mathrm{~h}$ in patients with inactive nephritis, $105.98 \pm 22.34 \mathrm{mg} / 24 \mathrm{~h}$ in patients without nephritis and $45.98 \pm 9.89 \mathrm{mg} / 24 \mathrm{~h}$ in the control group ( $p=$ $0.04)$.

Also, those patients with inactive nephritis had significantly higher $24 \mathrm{~h}$-protien in comparison to those without nephritis and the control group. There was no significant difference between patients without nephritis and the control group regarding $24 \mathrm{~h}$-urinary proteins $(105.98 \pm 22.34$ vs. $45.98 \pm$ $9.89 \mathrm{me} / \mathrm{day} ; p=0.85)$.

\section{3- Estimated GFR by CKD-EPI Creatinine Equa- tion $\left(\mathrm{mL} / \mathrm{min} / 1.73 \mathrm{~m}^{2}\right)$ :}

The current study showed that patients with nephritis whether active or inactive had significantly low estimated GFR (eGFR) $-55.13 \pm 12.01$ and $61.33 \pm 13.67 \mathrm{ml} /$ minute in comparison to those patients without nephritis and the control group $(p=0.001)$.

There was no significant difference between patients with active nephritis and those with inactive nephritis and also, there was no significant difference between those without nephritis and the control group regarding eGFR $(p>0.05)$.

\section{- Erythrocyte sedimentation rate (ESR):}

Patients with SLE (with or without nephritis) had significantly higher ESR in comparison to the control group with $p=0.001$. Those patients with active nephritis had significantly high ESR followed by those with inactive nephritis and those without nephritis.

\section{- C3 and C4 level:}

\section{1- C3 level:}

Patients without nephritis and the control group had significantly higher level of C3 $111.56 \pm 32.89$ and $122.93 \pm 25.89 \mathrm{mg} / \mathrm{dl}$ in comparison to those patients with active or inactive nephritis $(51.13 \pm$ 16.67 and $92.26 \pm 18.99 \mathrm{mg} / \mathrm{dl}$ with $p<0.05$ ).

\section{2- C4 level:}

Similar to C3; significantly lower level presented in patients with nephritis whether active or inactive while higher level was noticed in those without nephritis and the control group ( $p=0.04)$.

\section{- Anti-double strand antibodies (anti-DNA):}

All patients with active nephritis were positive for anti-DNA while only three patients from those with inactive nephritis and three from those without nephritis were positive. Equivocal result was noticed in 7 patients; 3 from them were without nephritis and the others had inactive nephritis $(p=0.001)$.

\section{- Anti -nuclear antibodies (ANA):}

Patients with SLE had significantly higher level of ANA in comparison to the control group ( $p=$ 0.001 ). Patients with nephritis either active or inactive had significantly higher level of ANA in comparison to those without nephritis $(66.78 \pm$ $15.08,48.67 \pm 12.87$ and $66.44 \pm 14.78$ respectively $=$ $0.001)$.

Systemic lupus erythematosus disease activity index (SLEDAI):

Based on renal SLEDAI score; it was noticed that none of patients without nephritis or with inactive nephritis had pyuria, proteinuria, cast or hematuria. A total of 7 (46.75), 5 (33.3\%), 13 $(86.7 \%)$ and $10(66.7 \%)$ patients from those with active nephritis had cast, pyuria, proteinuria and hematuria respectively. Patients with active nephritis had renal- SLEDAI $9.33 \pm 2.28$.

Urinary kidney injury m olecule 1 (U-Kim-1) in the studied subjects:

Generally U-Kim-1 was significantly higher in those patients with SLE compared with the healthy control group. Also, patients with nephritis had significantly higher level in comparison to those without nephritis. In the current study; it was noticed that patients with active nephritis had significantly higher level of U-Kim-1 in comparison to those patients with inactive nephritis (Table 4, Fig. 3).

Correlation of U-Kim-1 with serum creatinine, eGFR, C3, C4 and 24h-urinary proteins:

It was noticed that $\mathrm{u}$-Kim-1 had negative moderate significant correlation with eGFR $[-0.62$ (0.001)], and Complement C3 [-0.51 (0.001)] and had positive moderate significant correlation with serum creatinine [0.44 (0.001)], and renal SLEDAI [0.62 (0.001)].

There was a strong positive significant correlation between U-Kim-1 and 24h-urinary proteins collection [0.71 (0.001)].

Although there was negative weak correlation between U-Kim- 1 and complement C4, this correlation was insignificant $[-0.22(0.12)]$. 
Table (2): Laboratory Data of the studied groups.

\begin{tabular}{|c|c|c|c|c|c|}
\hline Variables & $\begin{array}{l}\text { Patients } \\
\text { without } \\
\text { nephritis } \\
(\mathrm{n}=15)\end{array}$ & $\begin{array}{l}\text { Patients with } \\
\text { inactive } \\
\text { nephritis } \\
(n=15)\end{array}$ & $\begin{array}{l}\text { Patients with } \\
\text { active } \\
\text { nephritis } \\
(\mathrm{n}=15)\end{array}$ & $\begin{array}{l}\text { Control } \\
\text { group } \\
(\mathrm{n}=15)\end{array}$ & $p$-value \\
\hline Total leucocytic count $\left(\times 10^{3} / \mathrm{ml}\right)$ & $7.67 \pm 1.45$ & $6.83 \pm 0.98$ & $6.88 \pm 1.11$ & $7.32 \pm 2.33$ & 0.94 \\
\hline Hemoglobin (g\%) & $9.75 \pm 1.09$ & $9.67 \pm 1.81$ & $9.18 \pm 2.11$ & $12.79 \pm 1.22$ & 0.001 \\
\hline Mean corpuscular volume & $84.46 \pm 6.99$ & $83.40 \pm 6.42$ & $84.66 \pm 7.77$ & $89.09 \pm 5.14$ & 0.12 \\
\hline Mean corpuscular hemoglobin & $27.13 \pm 2.99$ & $26.26 \pm 2.54$ & $25.77 \pm 5.88$ & $28.06 \pm 2.78$ & 0.19 \\
\hline Platelets $\left(\times 10^{3} / \mathrm{ml}\right)$ & $155.26 \pm 35.78$ & $193.8 \pm 55.87$ & $262.98 \pm 58.89$ & $303.99 \pm 74.55$ & 0.001 \\
\hline Serum albumin $(g / L)$ & $35.23 \pm 4.04$ & $29.93 \pm 5.56$ & $28.06 \pm 4.35$ & $38.13 \pm 2.73$ & 0.03 \\
\hline serum urea (mg/dl) & $30.24 \pm 7.78$ & $75.82 \pm 15.09$ & $108.09 \pm 19.98$ & $28.83 \pm 7.89$ & 0.001 \\
\hline Serum creatinine $(\mathrm{mg} / \mathrm{dl})$ & $0.78 \pm 0.21$ & $1.92 \pm 0.45$ & $2.90 \pm 0.98$ & $1.02 \pm 0.19$ & 0.01 \\
\hline 24h-urinary protein (mg/day) & $105.98 \pm 22.34$ & $1117.98 \pm 201.34$ & $1412.89 \pm 234.78$ & $45.98 \pm 9.89$ & 0.04 \\
\hline eGFR (ml/min/1.73m2) & $84.4 \pm 15.31$ & $61.33 \pm 13.67$ & $55.13 \pm 12.01$ & $103.66 \pm 26.94$ & 0.001 \\
\hline \multicolumn{6}{|l|}{ Erythrocyte sedimentation rate: } \\
\hline $1 \mathrm{st} \mathrm{h}(\mathrm{ml} / \mathrm{h})$ & $30.66 \pm 6.89$ & $49.67 \pm 12.67$ & $84.78 \pm 17.43$ & $7.66 \pm 1.44$ & 0.001 \\
\hline 2nd h $(\mathrm{ml} / \mathrm{h})$ & $49.78 \pm 11.45$ & $64.90 \pm 17.76$ & $111.93 \pm 25.67$ & $14.88 \pm 3.99$ & 0.001 \\
\hline \multicolumn{6}{|l|}{ Complement level ( $\mathrm{mg} / \mathrm{dl})$ : } \\
\hline $\mathrm{C} 3$ & $111.56 \pm 32.89$ & $92.26 \pm 18.99$ & $51.13 \pm 16.67$ & $122.93 \pm 25.89$ & 0.001 \\
\hline $\mathrm{C} 4$ & $33.90 \pm 8.94$ & $24.99 \pm 6.89$ & $15.89 \pm 4.44$ & $35.09 \pm 8.99$ & 0.04 \\
\hline Anti-double antibodies: & & & & & 0.001 \\
\hline Positive $(>60 \mathrm{U} / \mathrm{ml})$ & $8(53.3)$ & $9(60)$ & $15(100)$ & 0 & \\
\hline Equivocal (40-60 U/ml) & $4(26.7)$ & $3(20)$ & 0 & 0 & \\
\hline Negative $(<60 \mathrm{U} / \mathrm{ml})$ & $3(20)$ & $3(20)$ & 0 & 0 & \\
\hline ANA (U/L) & $48.67 \pm 12.87$ & $66.44 \pm 14.78$ & $66.78 \pm 15.08$ & $9.39 \pm 2.78$ & 0.001 \\
\hline
\end{tabular}

- Data was expressed in form of mean $\pm \mathrm{SD}$ or in form of frequency (percentage) as appropriate. $p$-value was significant if $<0.05$. N: Number

Table (3): Systemic lupus erythematosus disease activity index (SLEDAI) in the studied patients.

\begin{tabular}{lcccc}
\hline & $\begin{array}{c}\text { Patients } \\
\text { without nephritis } \\
(\mathrm{n}=15)\end{array}$ & $\begin{array}{c}\text { Patients with } \\
\text { inactive nephritis } \\
(\mathrm{n}=15)\end{array}$ & $\begin{array}{c}\text { Patients with } \\
\text { active nephritis } \\
(\mathrm{n}=15) \mathrm{n}(\%)\end{array}$ & $p$-value \\
\hline Urine analysis: & 0 & & & \\
$\quad$ Cast & 0 & 0 & $7(46.7)$ & 0.001 \\
Hematuria & 0 & 0 & $5(33.3)$ & 0.02 \\
Proteinuria & 0 & 0 & $13(86.7)$ & 0.001 \\
Pyuria & 0 & 0 & $10(66.7)$ & 0.001 \\
Renal SLEDAI- score & 0 & 0 & $9.33 \pm 2.28$ & 0.001 \\
\hline
\end{tabular}

- Data was expressed in form of mean \pm SD or in form of frequency (percentage) as appropriate. $p$-value was significant if $<0.05$. N: Number

Table (4): Laboratory Data of the studied groups.

\begin{tabular}{lccccc}
\hline Variables & $\begin{array}{c}\text { Patients } \\
\text { without nephritis } \\
(\mathrm{n}=15)\end{array}$ & $\begin{array}{c}\text { Patients with } \\
\text { inactive nephritis } \\
(\mathrm{n}=15)\end{array}$ & $\begin{array}{c}\text { Patients with } \\
\text { active nephritis } \\
(\mathrm{n}=15)\end{array}$ & $\begin{array}{c}\text { Control group } \\
(\mathrm{n}=15)\end{array}$ & $p$-value \\
\hline U-Kim-1 & $5.11 \pm 1.09$ & $11.28 \pm 2.55$ & $12.67 \pm 2.90$ & $2.09 \pm 0.76$ & 0.001 \\
\hline
\end{tabular}

- Data was expressed in form of mean $\pm \mathrm{SD}$ or in form of frequency (percentage). $p$-value was significant if $<0.05$. $\mathrm{N}$ : Number. 
Table (5): Correlation of U-Kim-1 with different variables in the study.

\begin{tabular}{lc}
\hline Parameters & $r(p)$ \\
\hline Serum creatinine & $0.44(0.001)$ \\
eGFR & $-0.62(0.001)$ \\
Complement C3 & $-0.5(0.001)$ \\
Complement C4 & $-0.22(0.12)$ \\
24h-urinary proteins & $0.71(0.001)$ \\
Renal SLEDAI score & $0.62(0.001)$ \\
\hline
\end{tabular}

= Data was expressed in form of $r$ : Indicated strength of association and $p: p$-value that was significant if $<0.05$.

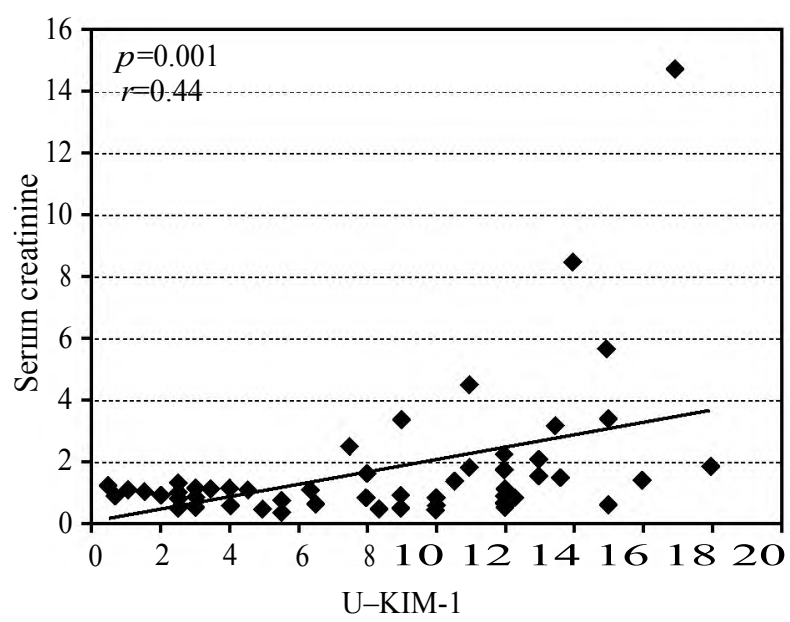

Fig. (4): Correlation between u-Kim-1 and serum creatinine.

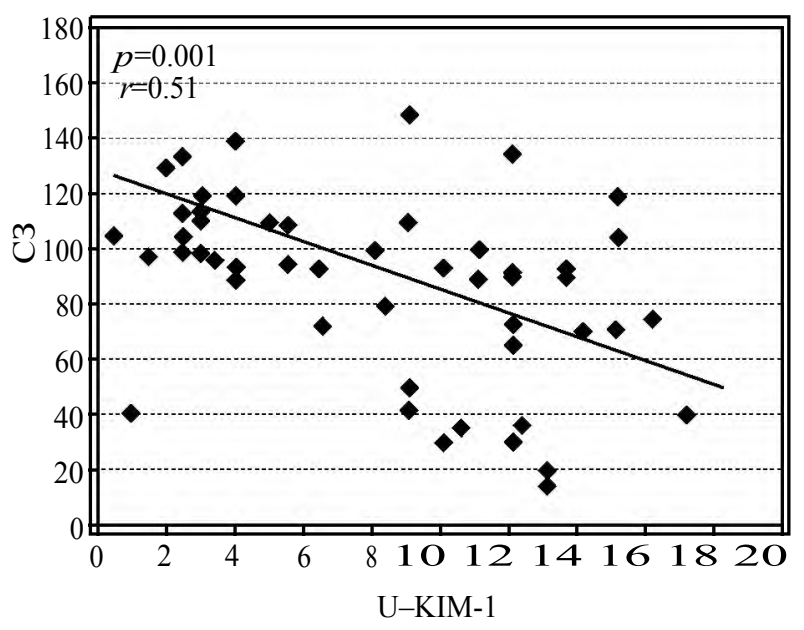

Fig. (6): Correlation between U-Kim-1 and C3.

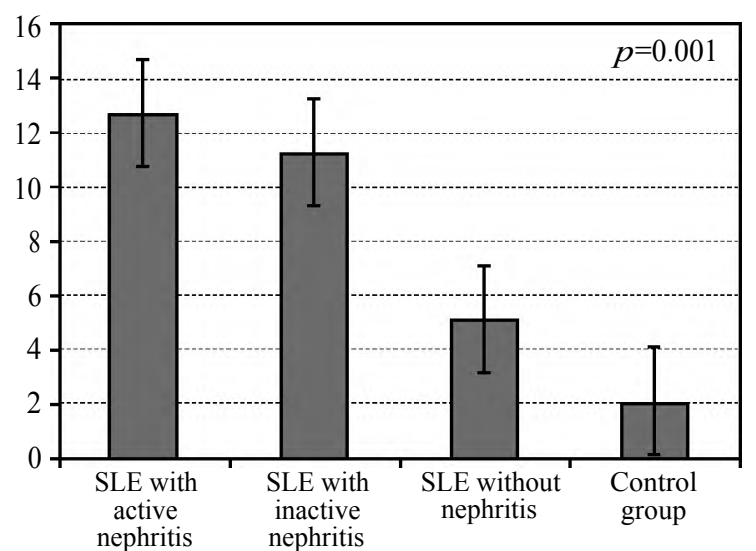

Fig. (3): Level of U-Kim-1 in the studied subjects.

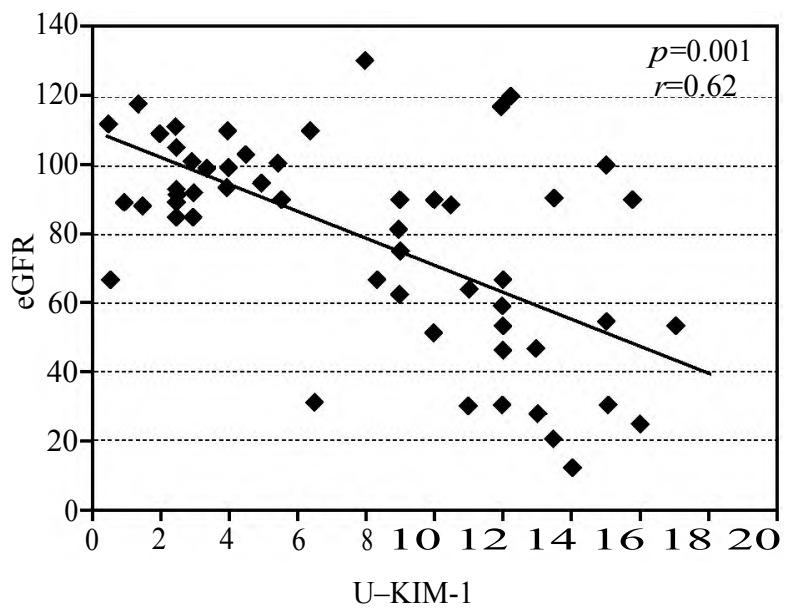

Fig. (5): Correlation between u-Kim-1 and eGFR.

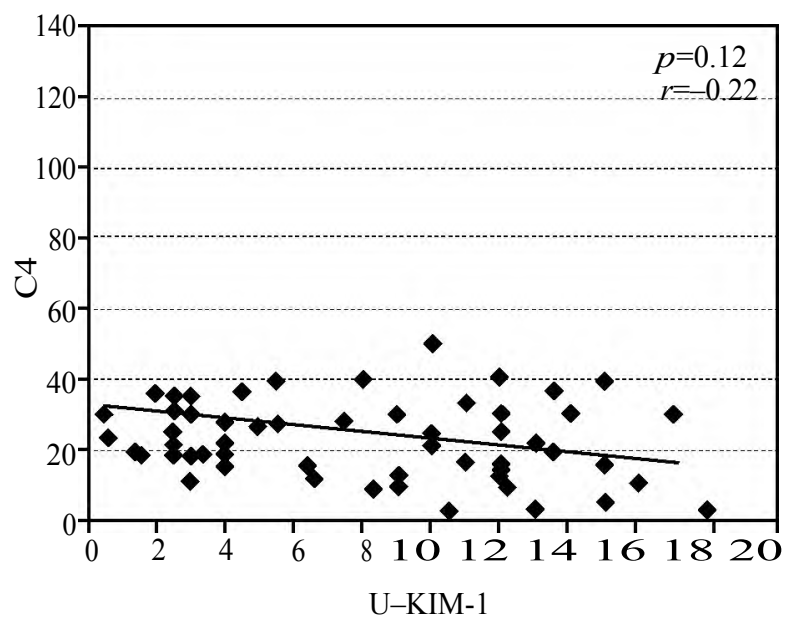

Fig. (7): Correlation between U-Kim-1 and C4. 


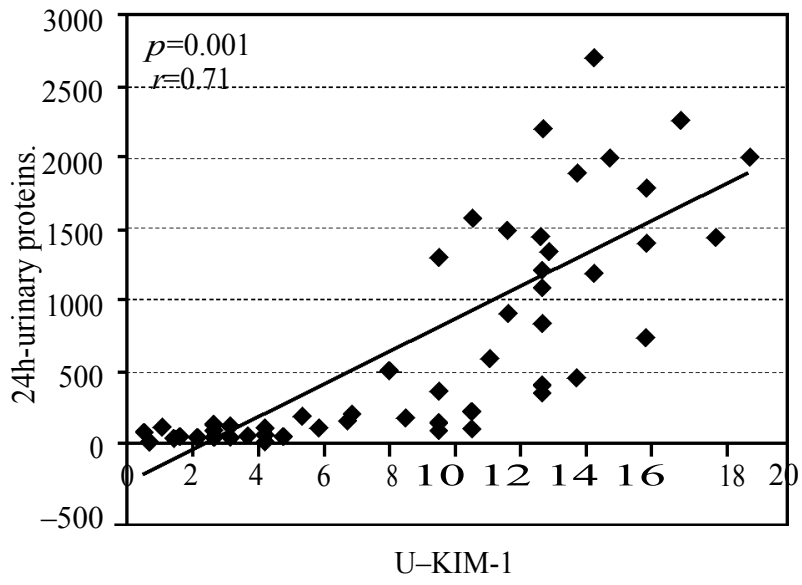

Fig. (8): Correlation between U-Kim-1 and 24h-urinary proteins.

\section{Discussion}

Systemic lupus erythematosus (SLE) is a prototypic autoimmune disease that is characterized by systemic chronic inflammation that can affect multiple major organ systems. A major cause of morbidity and mortality among patients with SLE is kidney affection, known lupus nephritis (LN) [14] . Lupus nephritis (LN) is known to be the most serious complication of SLE and the strongest predictor of poor outcome. Early detection and treatment of renal involvement can significantly improve renal outcome [15]. Our study is case control study which included 45 patients with SLE and 15 controls to evaluate role of urinary kidney injury molecule-1 (U-Kim-1) as a predictor of lupus nephritis in systemic lupus erythematous (SLE) patients. Our study showed that no significant sex difference between studied diseased groups $p$-value was 0.87 , which was in contrast with Julie and Chaim, study which showed that SLE typically affects females more than males; however male SLE patients often have more severe disease than females. Also lupus nephritis is more frequent in men than women, and several groups identified male gender as a risk factor for progression to renal failure. The specific differences in pathogenesis among genders may be due to genetic, hormonal, and immune responses. Further research is warranted to further study these differences [16] Laboratory data of our studied groups showed significant differences between the different groups of patients regarding serum albumin level ( $p=$ $0.04)$. Control group and patients without nephritis had significantly higher $(p<0.05)$ level in comparison to those with inactive nephritis and those with active nephritis. Patients with active nephritis had significantly higher 24-hr urinary proteins in comparison to other groups. Also, those patients with

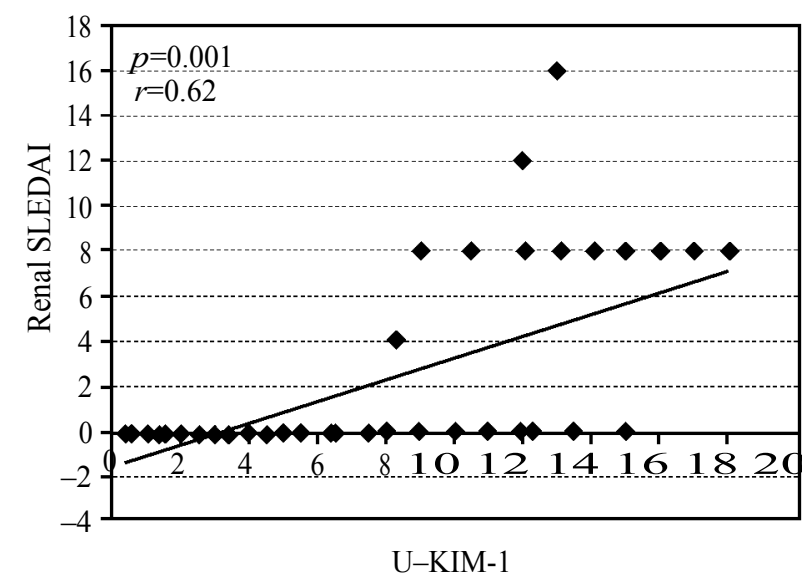

Fig. (9): Correlation between U-Kim-1 and renal SLEDAI.

inactive nephritis had significantly higher $24 \mathrm{~h}$ protien in comparison to those without nephritis and the control group. These results were consistent with Yip et al., who demonstrated that serum albumin is inversely associated with SLE disease activity and this association was stronger in those with LN and especially in those with proteinuria [17]. Also Sui and Jia,who highlight in their paper that nephrotic-range proteinuria, elevated total cholesterol level and decreased serum albumin levels may reflect the activity and severity of renal damage in SLE patients [18]

Patients without nephritis and the control group had significantly higher level of C3 and C4 in comparison to those patients with active or inactive nephritis $p<0.05$. That was consistent with Narayanan et al., who observed in their prospective study that 12 out of $13(92.3 \%)$ patients with active renal involvement had low C3 levels and $11(84.6 \%)$ had low $\mathrm{C} 4$ levels.Low $\mathrm{C} 3$ and $\mathrm{C} 4$ levels were noticed in $43 \%$ and $53 \%$ of non-renal flares respectively. There is a negative correlation between SLEDAI scores and both $\mathrm{C} 3$ and $\mathrm{C} 4$ levels in renal flares [19]. Petri et al., in their prospective cohort study of 185patients with SLE had observed decrease in $\mathrm{C} 3$ and $\mathrm{C} 4$ titres in $44 \%$ and $41 \%$ of the disease flares respectively [20]

However, Birmingham et al., study demonstrates the poor clinical utility of serial serum $\mathrm{C} 3$ or $\mathrm{C} 4$ measurements alone to forecast or identify an SLE renal flare [21]

The reasons for the discrepancies across studies are multifactorial, including differences in study design, ethnicity, baseline clinical characteristics and renal parameters. 
All patients with active nephritis in our study were positive for anti-DNA while only three patients from those with inactive nephritis and three from those without nephritis were positive. Many studies proved that Anti-dsDNA antibodies are considered as'serological markers' for SLE and associated with $\mathrm{LN}$ activity and prognosis $[22,23]$ Linnik et al., in a multicenter study of 487 lupus nephritis cases found that changes in the titer of anti-dsDNA measured by a Farr assay correlated with a risk of renal flares and was inversely correlated with serum C3 levels [24]. Narayanan et al., found that the anti-dsDNA levels were elevated in all patients with predominant renal flare. In nonrenal flare anti-dsDNAtitre was raised only in 35\% cases. There is a strong positive correlation between SLEDAI scores and anti-dsDNA levels [19]. The factors associated with $\mathrm{LN}$ outlined in the Ouraniaet al., study are the presence of anti-dsDNA, anti-Sm antibodies and of LA [25]. However, in a prospective study of 53 SLE patients, Ho et al., reported that at the time of lupus flares including renal flares, the serum titer of anti-dsDNA often decreased after a previous rise. As per the authors, the decrease may represent deposition of immune complexes during the disease flare [24]. In Fu et al., review provides evidence that anti-dsDNA antibodies have a limited value in the diagnosis of SLE. These antibodies are useful in confirming the diagnosis in the clinical settings when SLE is likely to be the diagnosis. They have limited usefulness in monitoring disease activities and in predicting flares. In contrast to the current dogma that these antibodies may initiate lupus nephritis, they are not necessary or sufficient to cause lupus nephritis [26].

Patients with SLE in our study had significantly higher level of ANA in comparison to the control group ( $p=0.001)$. Patients with nephritis either active or inactive had significantly higher level of ANA in comparison to those without nephritis. Lupus nephritis is generally associated with ANA positivity [27]. However, ANA is negative in approximately $5 \%$ of patients diagnosed as SLE [28] Lupus nephritis is frequently associated with ANA and anti-dsDNA. On rare occassions, the serological markers may be initially absent, but they become positive after some time in most patients [29] Wistowska et al., mentioned that higher values of ANA and anti-dsDNA antibodies were found more often in patients with lupus nephritis [30]

Studies in human indicated that urinary KIM1 was sensitive and specific marker of kidney injury as well as predictors of outcome [8].
In our study UKim-1 was significantly higher in our patients with SLE compared with the healthy control group. Also, patients with nephritis had significantly higher level in comparison to those without nephritis. Our study also showed that patients with active nephritis had significantly higher level of U-Kim-1 in comparison to those patients with inactive nephritis. Nozaki et al., have also concluded in their cross-sectional study that Kim-1 is elevated in SLE patients with LN and is closely associated with renal disease severity. U-Kim-1 levels and t-Kim-1 expression were markedly elevated in active LN with different extents of tubular atrophy and fibrosis, interstitial fibrosis, and inflammatory cell infiltration [4]. In previous studies, the U-Kim-1 levels were elevated in CKD patients including those with $\mathrm{LN}$, and they were correlated with tubulointerstitial lesions $[31,32]$

Our study showed that U-Kim-1 had negative moderate significant correlation with eGFR $[-0.62$ (0.001)], and Complement C3 [-0.51 (0.001)] and had positive moderate significant correlation with serum creatinine [0.44 (0.001)], and renal SLEDAI [0.62 (0.001)]. There was also a strong positive significant correlation between U-Kim-1 and 24hurinary proteins collection $[0.71(0.001)]$. Although there was negative weak correlation between UKim-1 and complement $\mathrm{C} 4$, this correlation was insignificant $[-0.22(0.12)]$.

Nozaki et al., results showed that the U Kim1 levels were also significantly correlated with proteinuria $(r=0.39 ; p=0.004)$. The U-Kim- 1 levels at baseline were significantly correlated with eGFR $(r=-0.72 ; p=0.005)$ and $\mathrm{sCr}(r=0.53 ; p=0.005)$ after 6-8 months of treatment, but there was no correlation between the U-Kim-1 levels at baseline and the urinary protein-to-Cr ratio after 6-8 months of treatment of active lupus nephritis. U-Kim-1 levels and $\mathrm{t}-\mathrm{Kim}-1$ expression correlated with renal parameters of disease activity and histological severity, but not with systemic parameters of lupus disease activity (the total SLEDAI, anti-DNA antibodies, and C4) [4].

Several studies indicated use of Ukim-1 as a predictor or a biomarker with other forms of renal injury including (Tubular injury, AKI, CKD, CIN, Diabetic nephropathy, Drug induced nephropathy ...etc) [33-39]

Lobato et al., study detected a trend toward increased baseline levels of KIM-1 and NGAL in patients with renal impairment who progressed to more advanced stages of CKD [40] 
Therefore elevations in U Kim-1 levels are not specific to nephritis in SLE; However,this does not detract from a potentially valuable role for Kim-1 in lupus patients as suggested by the results of our study, in the initial diagnosis of kidney involvement, or in subsequent monitoring of disease activity.

In conclusion, urinary kidney injury molecule $-1(\mathrm{KIM}-1)$ is considered a promising biomarker that can be used in early detection and initial diagnosis of renal affection in systemic lupus erythrematosus, monitoring of activity of lupus nephritis. And hence, can also be used in monitoring response to treatment.

Recommendation: Our study recommends wider studies to detect cut off points of U-Kim-1 in lupus nephritis \& active lupus nephritis. Also, more studies that include more patients , new biomarkers and laboratory methods are needed for early screening of systemic lupus patients, early detection of lupus nephritis and hence, early biopsy taking and classification of lupus nephritis. And in turn that lead to early management of lupus nephritis patients and thorough follow-up of disease activity $\&$ response to treatment.

\section{References}

1- KORBET S.M., LEWIS E.J., SCHWARTZ M.M., REICHLIN M., EVANS J. and ROHDE R.D.: Factors predictive of outcome in severe lupus nephritis. Am. J. Kidney. Dis., 35: 904-914, 2000.

2- LIVINGSTON B., BONNER A. and POPE J.: Differences in clinical manifestations between childhood-onset lupus and adult-onset lupus: A meta-analysis. Lupus. Nov., 20 (13): 1345-55, 2011.

3- FIEHN C., HAJJAR Y., MUELLER K., WALDHERR R., HO A.D. and ANDRASSY K.: Improved clinical outcome of lupus nephritis during the past decade: Importance of early diagnosis and treatment. Ann Rheum Dis., 62: 435439, 2003.

4- NOZAKI Y., KINOSHITA K., YANO T., SHIGA T., HINO S., et al.: Estimation of kidney injury molecule-1 (Kim-1) in patients with lupus nephritis. Lupus, 2014.

5- ILLEI G.G., TACKEY E., LAPTEVA L. and LIPSKY P.E.: Biomarkers in systemic lupus erythematosus, General overview of biomarkers and their applicability. Arthritis Rheum., 50: 1709-1720, 2004.

6- ICHIMURA T., BONVENTRE J.V., BAILLY V., WEI H., HESSION C.A., CATE R.L., et al.: Kidney injury molecule-1 (KIM-1), a putative epithelial cell adhesion molecule containing a novel immunoglobulin domain, is up-regulated in renal cells after injury. J. Biol. Chem., 273: 4135-4142, 1998.

7- WAANDERS F., VAN TIMMEREN M.M., STEGEMAN C.A., BAKKER S.J. and VAN GOOR H.: Kidney injury molecule-1 in renal disease. J. Pathol., 220: 7-16, 2010.
8- BONVENTRE J.V.: Kidney Injury Molecule-1 (KIM-1): A specific and sensitive biomarkerof kidney injury. Scand J. Clin .Lab. Invest. Suppl., 241: 78-83, 2008.

9- TAN E.M., COHEN A.S., FRIES J.F., MASI A.T., et al.: The revised criteria for the classification of systemic lupus erythematosus. Arthritis Rheum. 25: 1271-7, 1982.

10- HOCHBERG M.C.: Updating the American College of Rheumatology revised criteria for the classification of systemiclupus erythematosus [letter]. Arthritis Rheum., 40: 1725, 1997.

11- GLADMAN D.D., IBANEZ D. and UROWITZ M.B.: Systemic lupus erythematosus disease activity index. J. Rheumatol., 29: 288-291, 2002.

12- CHAN R.W., LAI F.M., LI E.K., et al.: The effect of immunosuppressive therapy on the messenger RNA expression of target genes in the urinary sediment of patients with active lupus nephritis. Nephrol. Dial Transplant, 21: 1534-1540, 2006

13- BOMBARDIER C., GLADMAN D.D., UROWITZ M.B., CARON D. and CHANG C.H.: Derivation of the SLEDAI. A disease activity index for lupus patients. The Committee on Prognosis Studies in SLE. Arthritis Rheum., 35: 63040, 1992.

14- KOUTSOKERAS T. and HEALY T.: Systemic Lupus Erythematosus and Lupus Nephritis - Global Drug Forecast and Market Analysis to 2022 Pharma Point, 2013.

15- KAUL A., GORDON C., MARY K., et al.: Systemic Lupus Erythematosus. Nature Reviews Disease Primers 2, Article number: 16039, 2016.

16- JULIE S.M. and CHAIM P.: Gender Differences in the Pathogenesis and Outcome of Lupus and of Lupus Nephritis. Clinical and Developmental Immunology. Article ID 604892, 9 pages, 2012.

17- YIP J., AGHASSI E., JIANDONG S.U., et al.: Serum Albumin as a Marker for Disease Activity in Patients with Systemic Lupus Erythematosus. The Journal of Rheumatology, 37 (8): 1667-1672, 2010.

18- SUI M., JIA X., CHENGYUAN Y.U. et al.: Relationship between hypoalbuminemia, hyperlipidemia and renal severity in patients with lupus nephritis: A prospective study. Centr. Eur. J. Immunol., 39 (2): 243-252, 2014.

19-NARAYANAN K., MARWAHA V., SHANMUGANANDAN K. and SHANKAR CAPT S.: Correlation between Systemic Lupus Erythematosus Disease Activity Index, C3, C4 and Anti-dsDNA Antibodies. MJAFI, Vol. 66, No. 2, 2010 .

20- PETRI M., GENOVESE M., ENGLE E. and HOCHBERG M.: Definition, incidence and clinical description of flare in systemic lupus erythematosus: A prospective cohort study. Arthritis Rheum., 34: 937-44, 1991.

21- BIRMINGHAM D.J., IRSHAID F., NAGARAJA H.N., et al.: The complex nature of serum $\mathrm{C} 3$ and $\mathrm{C} 4$ as biomarkers of lupus renal flare; Lupus, 19: 1272-1280, 2010.

22- ISENBERG D.A., RAVIRAJAN C.T., RAHMAN A., KALSI J.: The role of antibodies to DNA in systemic lupus erythematosus-a review andintroduction to an international workshop on DNA antibodies. Lupus, 6 (3): 290-304, 1997. 
23- HO A., MAGDER L.S., BARR S.G. and PETRI M.: Decreases in anti-doublestranded DNA levels are associated with concurrent flares in patients with systemic lupus erythematosus. Arthritis Rheum., 44 (10): 2342-9, 2001.

24- LINNIK M.D., HU J.Z. and HEILBRUNN K.R.: Relationship between antids DNA antibodies and exacerbation of renal disease in patients with systemic lupus erythematosus. Arthritis Rheum., 52: 1129-37, 2005.

25- OURANIA D., RICAIOANA, ANDREEA B., ANCA M. and PAULINA C.: Immunological Profile in Patients with Lupus Nephritis and Correlations with the Histological Pattern. Current Health Sciences Journal, Vol., 37, No. 4., 2011.

26- FU S.M., DAI C., ZHAO Z. and GASKIN F.: Anti-dsDNA Antibodies are oneof the many autoantibodies in systemic lupus erythematosus F1000Research, 4 (F1000 Faculty Rev): 939, 2015.

27- BAGAVANT H., DESHMUKH U.S., GASKIN F. and FU S.M.: Lupus glomerulonephritis revisited: Autoimmunity and end-organ damage. Scand. J. Immunol., 60: 5263, 2004.

28- SUNG C.K. and KUN E.W.L.: A young lady with fullhouse nephropathy and negative anti-nuclear antibody. Hong Kong Bull Rheum. Dis., 9: 23-25, 2009.

29- COBEÑAS C.J., SPIZZIRI F.D. and DRUT R.: Membranous nephropathy and seronegative systemic lupus erythematosus. Pediatr. Nephrol., 18 (2): 202-3, 2003.

30- WISTOWSKA M., GOZDOWSKA J. and KORCZ T.: The importance of serological and histopathological diagnosis of the different forms of systemic lupus erythematosus with and without lupus nephritis. Int. J. Clin. Rheumatol., 9 (6): 21-29 ISSN 1758-4272, 2014.

31- NOZAKI Y., NIKOLIC-PATERSON D.J., SNELGROVE S.L., et al.: Endogenous Tim-1 (Kim-1) promotes T-cell responses and cell-mediated injury in experimental crescentic glomerulonephritis. Kidney Int., 81: 844-855, 2011.

32- PETERS H.P., WAANDERS F., MEIJER E., et al.: High urinary excretion of kidney injury molecule- 1 is an inde- pendent predictor of end-stage renal disease in patients with IgA nephropathy. Nephrol. Dial. Transplant., 26: 3581-3588, 2001.

33- TIAN L., SHAO X., XIE Y., et al.: Kidney Injury Molecule1 is Elevated in Nephropathy and Mediates Macrophage Activation via the Mapk Signalling Pathway. Cell. Physiol. Biochem., 41 (2): 769-783, 2017.

34- FADHIL J.A., MAHA H.D. and RYIADH M.A.: Measurement of urinary kidney injury molecule- 1 as a predictive biomarker of contrast-induced acute kidney injury. Research ISSN, 2413-0516, 2017.

35- ESMERALDA C.R. ,RAUL F.P., CATALINA M.C. et al.: Kidney Injury Marker 1 and Neutrophil GelatinaseAssociated Lipocalin in Chronic Kidney Disease.Nephron Clinical Practice, 2016.

36- CARSTEN G., JUNGBAUER, EKREMUECER, et al.: $\mathrm{N}$-acteyl- $\beta$-D-glucosaminidase and kidney injury molecule-1: Newpredictors for long-term progression of chronic kidney disease in patients with heart failure, University Hospital Regensburg. Nephrology, 21: 490-498, 2016.

37- JOSÉ ANTONIO M., ETIANE T., BRUNA S., et al.: Urinary kidney injurymolecule-1 and neutrophil gelatinaseassociated lipocalin as indicators oftubular damage in normoalbuminuric patients with type 2 diabetes. Clinical Biochemistry, 49: 232-236, 2016

38- CHIA H.Y., CHIH H.C., TIENHC, et al.: Combinations of Urinary Biomarkers Improves Early Detection of Acute Kidney Injury in Patients with Heart Failure. Circulation Journal, Vol 80, No. 4 p.1017-1023, 2016.

39- MIRA P., CASSIANNE R.C., ALICIA S.C. et al.: Detection of Drug-Induced Acute Kidney Injury inHumans Using Urinary KIM-1, miR-21, -200c, and -423. Toxicological Sciences, 152 (1): 205-213, 2016.

40- LOBATO G.R., LOBATO M.R., THOMÉ F.S.: Performance of urinary kidney injury molecule-1, neutrophil gelatinase-associated lipocalin, and $\mathrm{N}$-acetyl-b-Dglucosaminidase to predict chronic kidney disease progression and adverse outcomes. Braz. J. Med. Biol. Res., ISSN 1414-431X, 2017. 


\section{جزئ إصابة الكلى الأول فى البول كعامل كشف عن إلتهابات الكلى التهرئ

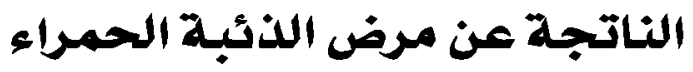

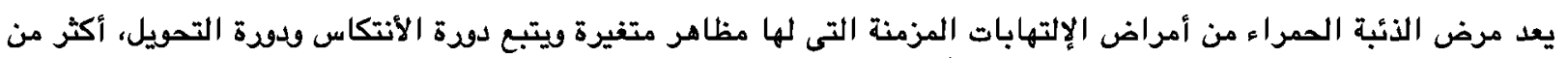

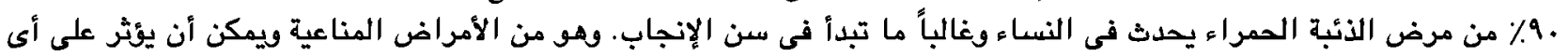

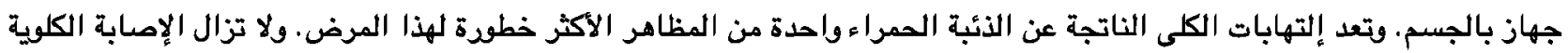

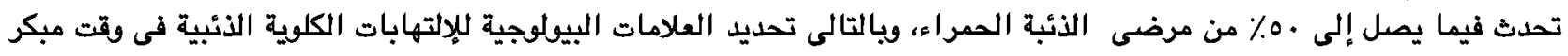

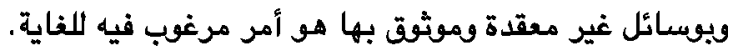

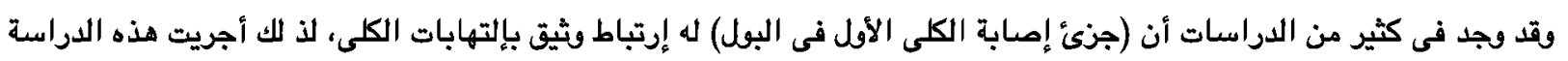

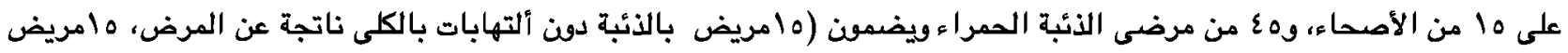
بالألتهابات الكلوية الغير نشطة، هالأمريض بالألتهابات الكلوية الذئبية النشطة).

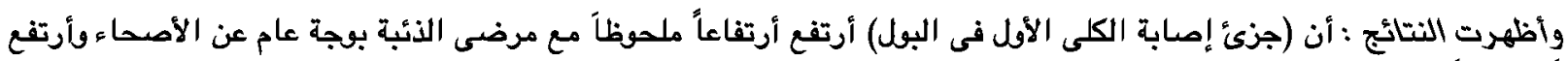

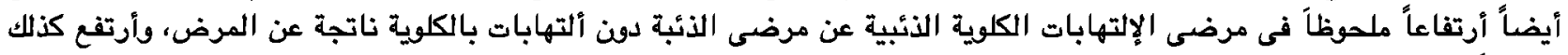
أرتفاعاً ملحوظاً فى مرضى الألتهابات الكلوية الذئيبية عن تلك الغير الغير نشيطة.

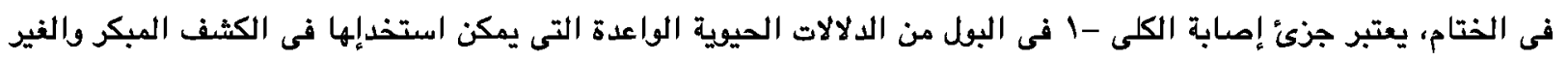

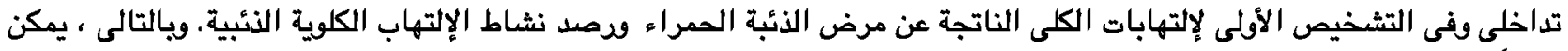
أيضاً أن يستخدم فى رصد الإستجابة للعلاج. 